\title{
Use of personal protective equipment during infectious disease outbreak and nonoutbreak conditions: a survey of emergency medical technicians
}

\author{
Laura M. Visentin, MSc; ${ }^{*}$ Susan J. Bondy, PhD;* Brian Schwartz, MD; $\$ \llbracket$ \\ Laurie J. Morrison, MD, MSc ${ }^{\dagger \dagger}$
}

\begin{abstract}
Objective: We sought to assess the knowledge of, use of and barriers to the use of personal protective equipment for airway management among emergency medical technicians (EMTs) during and since the 2003 Canadian outbreak of Severe Acute Respiratory Syndrome (SARS).

Methods: Using a cross-sectional survey, EMTs in Toronto, Ont., were surveyed 1 year after the SARS outbreak during mandatory training on the use of personal protective equipment in airway management during the outbreak and just before taking the survey. Practices that were addressed reflected government directives on the use of this equipment. Main outcome measures included the frequency of personal protective equipment use and, as applicable, why particular items were not always used.

Results: The response rate was $67.3 \%(n=230)$. During the SARS outbreak, an N95-type particulate respirator was reported to be always used by $91.5 \%$ of respondents. Conversely, $72.9 \%$ of the respondents reported that they never used the open face hood. Equipment availability and vision impairment were often cited as impediments to personal protective equipment use. In nonoutbreak conditions, only the antimicrobial airway filter was most often reported to be always used $(52.0 \%)$, while other items were used at an intermediate frequency. The most common reason for not always donning equipment was that paramedics deemed it unnecessary for the situation.

Conclusion: Personal protective equipment is not consistently employed as per medical directives. Reasons given for nonuse included nonavailability, judgment of nonnecessity or technical difficulties. There are important public health implications of noncompliance.
\end{abstract}

Keywords: Infectious disease, outbreak, emergency medical system, prehospital medicine, paramedics, population survey

\section{RÉSUMÉ}

Objectif : Nous avons cherché à évaluer la connaissance des appareils de protection respiratoire, la prévalence d'utilisation et les obstacles à leur utilisation pour la protection des voies respiratoires chez les techniciens médicaux d'urgence (TMU) pendant et depuis l'éclosion du syndrome respiratoire aigu sévère (SRAS) au Canada.

From the *Dalla Lana School of Public Health, University of Toronto, Toronto, Ont;; the TSunnybrook Health Sciences Centre, Toronto, Ont.; the ¥Division of Emergency Medicine, Department of Medicine, University of Toronto, Toronto, Ont.; the §Sunnybrook Osler Centre for Prehospital Care, Toronto, Ont.; and the IDepartment of Family and Community Medicine, University of Toronto, Toronto, Ont.

Submitted Feb. 12, 2008; Revised June 12, 2008; Accepted July 8, 2008

This article has been peer reviewed.

CJEM 2009;11(1):44-56 
Méthodes : Nous avons mené une enquête transversale auprès des TMU, à Toronto, en Ontario, 1 an après l'éclosion de SRAS, alors qu'ils suivaient une formation obligatoire sur l'emploi d'appareils de protection respiratoire. Les TMU ont été interrogés sur leurs pratiques pendant l'épidémie et au cours de la période précédant l'enquête. Les pratiques mentionnées dans l'étude reflétaient les lignes directrices du gouvernement sur l'usage de ces appareils. Les principales mesures de résultats comprenaient l'utilisation de ces appareils et, le cas échéant, la raison pour laquelle certains appareils n'étaient pas toujours utilisés.

Résultats : Le taux de réponse était de $67,3 \%(n=230)$. Au cours de l'épidémie de SRAS, $91,5 \%$ des répondants ont déclaré avoir porté un respirateur à filtre de particules comme le masque N95. En revanche, $72,9 \%$ des répondants ont indiqué qu'ils n'avaient jamais porté la cagoule recouvrant complètement la tête. La disponibilité des appareils et le fait que certains puissent gêner la vue ont souvent été cités comme des obstacles à leur utilisation. En temps de non-épidémie, le filtre à air antimicrobien était le seul le plus souvent cité par les répondants comme ayant toujours utilisé $(52,0 \%)$, alors que les autres dispositifs étaient utilisés à une fréquence intermédiaire. La raison la plus couramment citée pour laquelle les ambulanciers paramédicaux n'avaient pas utilisé de protection respiratoire était qu'ils ne la jugeaient pas nécessaires en situation non épidémique. Conclusion : Les appareils de protection respiratoire ne sont pas toujours utilisés conformément aux lignes directrices médicales. La non-disponibilité de l'équipement, la présumée non-nécessité ou des difficultés techniques étaient les raisons citées. Il faut savoir que la non-conformité à ces lignes directrices a des conséquences graves pour la santé publique.

\section{Introduction}

Awareness of the possibility of communicable disease outbreaks (as a result of either emerging infectious disease or bioterrorism attacks) is essential for emergency medical technicians (EMTs) and all health care workers. The Severe Acute Respiratory Syndrome (SARS) outbreaks in Toronto, Ont., and Hong Kong in 2003 were associated with high mortality and morbidity, and had a serious impact on health care delivery. ${ }^{1,2}$ Although it is important not to create an atmosphere of fear or panic, this experience demonstrated that an unanticipated respiratory disease outbreak could readily disrupt the normal health, social and economic systems.

EMTs are front-line health care workers who are at risk for contracting and spreading disease during an infectious outbreak of any kind. They are the first point of contact to the health care system and routinely respond to undefined respiratory complaints. ${ }^{3}$ During the SARS outbreak in Toronto, EMTs were among the first health care providers to become exposed, providing care to 4 of the initial 9 cases. ${ }^{4}$ Additionally, EMTs work in an uncontrolled, outof-hospital setting and have access to fewer human resources, equipment and expert support, as compared with those in an in-hospital setting. EMTs are often called to a scene in which there is little patient information from which to make a preliminary diagnosis or assess the risk of infection. These working conditions place these health care providers at a heightened risk for exposure to communicable respiratory diseases.

The primary means of protection for EMTs is through the use of personal protective equipment. These garments and devices are meant to protect EMTs from body fluids and respiratory droplets, which are considered to be an important route of spread for SARS and other respiratory infections. ${ }^{5,6}$ The decrease in the spread of SARS that was documented in the in-hospital setting after the implementation of mandatory infection control directives supports the effectiveness of personal protective equipment. ${ }^{7}$ Although there is no direct evidence of similar results in an out-ofhospital setting, the use of personal equipment would probably provide equal protection in this setting. Further, in Toronto, the SARS outbreak created a bimodal distribution for the system as a whole in which a lull in cases created a false sense of security and a reduction in the use of personal protective equipment. This was associated with the second outbreak peak. ${ }^{7}$ Subsequent to the first outbreak of SARS, the Ontario Ministry of Health and Long-term Care issued directives in May 2003. ${ }^{8}$ These directives were put in place to mandate the use of personal protective equipment with all patients during airway procedures, thus becoming the "new normal." This was intended to protect health care providers from any future unidentified outbreak. Moreover, it was designed to implement an appropriate level of protection for EMTs who might be exposed to smaller (community) outbreaks.

The objective of our study was to examine how compliant Toronto EMTs were to the personal protective equipment directives, first during the SARS outbreak and then again in the postoutbreak "new normal" situation. A secondary objective was to identify barriers to use of such equipment. 


\section{Methods}

\section{Setting}

As part of a publicly funded universal health care benefit program, all Ontario emergency medical services are partially funded by and accountable to the Ontario Ministry of Health and Long-Term Care. Medical control and oversight are provided by a designated base hospital for each region of the province. For the defined Greater Toronto Area, EMTs are employed by Toronto Emergency Medical Services, which is the sole service providing emergency medical response, including all ambulance services, to this city of over 2.5 million people.

EMT procedures are governed by uniform directives. At the time of our survey, all EMTs were operating under base hospital medical directives, which were updated in June 2003, and which outlined personal protective equipment use during outbreak conditions and during airway management regardless of the existence of a current outbreak. According to the directives, all Toronto Emergency Medical Services ambulances are required to be stocked with personal protective equipment including respirators, gowns and gloves. ${ }^{10}$

\section{Target population}

The target population for our study comprised all EMTintermediates, who are trained in the use of defibrillators and limited drug administration, and EMT-paramedics, who are trained in all aspects of advanced life support including airway management. These emergency response personnel provide care and perform procedures that carry the risk of infectious disease transmission; these procedures include cardiopulmonary resuscitation, control of hemorrhage, oxygen administration, immobilization and comfort measures. Both levels of EMTs are involved in advanced airway procedures. Both complete a 2-year college diploma course, but EMT-paramedics have an additional year of didactical and practical training. Defibrillation-only trained EMTs, who do not routinely perform high-risk manoeuvres such as advanced airway maintenance, and specialized critical care paramedics, who do not routinely respond to 911 calls, were excluded from the study.

\section{Survey instrument and materials}

The survey instrument consisted of a cover letter and a 4-page self-completed questionnaire, which took approximately 10-15 minutes to complete. The study was undertaken after the SARS outbreak in Toronto, which occurred in 2003 and followed a bimodal distribution with the first outbreak lasting from Mar. 21 to May 14, 2003, and the second outbreak lasting from May 23 to July 3, 2003. ${ }^{4}$ The questionnaire made reference to these time periods, and asked EMTs about their past behaviour in donning personal protective equipment during 2 described situations: 1) during the second 2003 Toronto-area SARS outbreak (June 2003); and 2) post-SARS, during the months immediately before the survey (a period of nonoutbreak conditions that took place in April/May 2004). The frequency of donning an individual personal protective equipment item was measured using a 5-point Likert-type scale ranging from always to never. For any response other than always, participants were asked their reasons for not always using personal protective equipment by using closed-ended options (checking all that apply) and an open-ended other option. Their knowledge of personal protective equipment requirements, reflecting those outlined in medical directives, was assessed using a series of true or false and multiplechoice responses to a series of questions presenting specific patient situations. Sample questions and the question format for self-reported behaviour and knowledge are demonstrated in Box 1, and the full questionnaire appears in Appendix 1. Demographic data obtained included age group, sex, the highest level of education completed, professional certification level, years of experience (in categories) and household structure (the presence of a spouse or partner and children $<18 \mathrm{yr}$ ).

\section{Procedure}

Surveys were completed anonymously and without the possibility of linking completed questionnaires to personal identifiers. Because of the sensitive nature of the study, which assessed work performance in compliance with mandatory directives, consent was also anonymous. A written cover letter indicated that completion of the questionnaire constituted consent. Participants could not be observed by supervisors while completing questionnaires and were free to submit a blank questionnaire. Ethical review and approval were obtained from the Sunnybrook and Women's College Research Ethics Board.

Data collection was carried out between Apr. 21 and June 1, 2004, during 28 sessions of 1-day continuing medical education.

\section{Results}

Of the 463 EMT-intermediate or -paramedic personnel with Toronto Emergency Medical Services at the time of the study, 342 attended the designated education sessions and were approached for the study. The remaining providers did not attend these training dates and would 
ordinarily be required to attend fall sessions; they were consequently not approached for this study. Of the 342 individuals approached for the study, 230 returned completed questionnaires resulting in a participation rate of $67.3 \%$ (Fig. 1).

Respondent characteristics are presented in Table 1. Of all participants, $63 \%$ were certified at the EMT-paramedic level and $93.5 \%$ had been on the job during the previous SARS outbreak. Most respondents were male (77.6\%).
The largest proportion of EMTs was between 30 and 39 years of age (45.6\%). Data on the characteristics of the study target population (i.e., the 463 EMT-intermediate or -paramedic personnel with Toronto Emergency Medical Services at the time of the study) have never been published. However, staff of the Toronto Emergency Medical Services provided us with aggregated demographic information on this group of employees from human resources records (Dean Popov, Toronto Emergency Medical

\section{Box 1. Key examples of survey content and format for survey regarding personal protective equipment use, Toronto Emergency Medical Services}

Examples of question structure for SELF-REPORTED BEHAVIOUR with respect to use of personal protective equipment. These questions were asked with reference to both the 2003 Toronto-area SARS outbreak and post-SARS during the time period immediately before the survey:

Part 1: In the last 10 encounters in which I performed or assisted with airway management, I wore: (check one)

$\begin{array}{lcccc} & \text { Always } & \text { Most of the time } & \text { Sometimes } & \text { Seldom }\end{array}$
eyewear

Part 2: If you indicated anything other than ìlways " for any item in the previous question, please indicate the reason(s) why you did not wear the personal protective equipment (check all that apply):

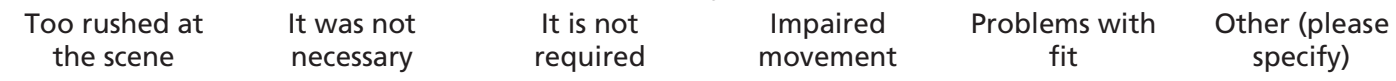

e.g., protective the scene necessary

required

movement

fit specify)

eyewear

Example of question structure for KNOWLEDGE with respect to use of personal protective equipment:

e.g., N95 or equivalent respirators must be fit tested to ensure proper protection.

$\square$ True

$\square$ False

SARS = severe acute respiratory syndrome.

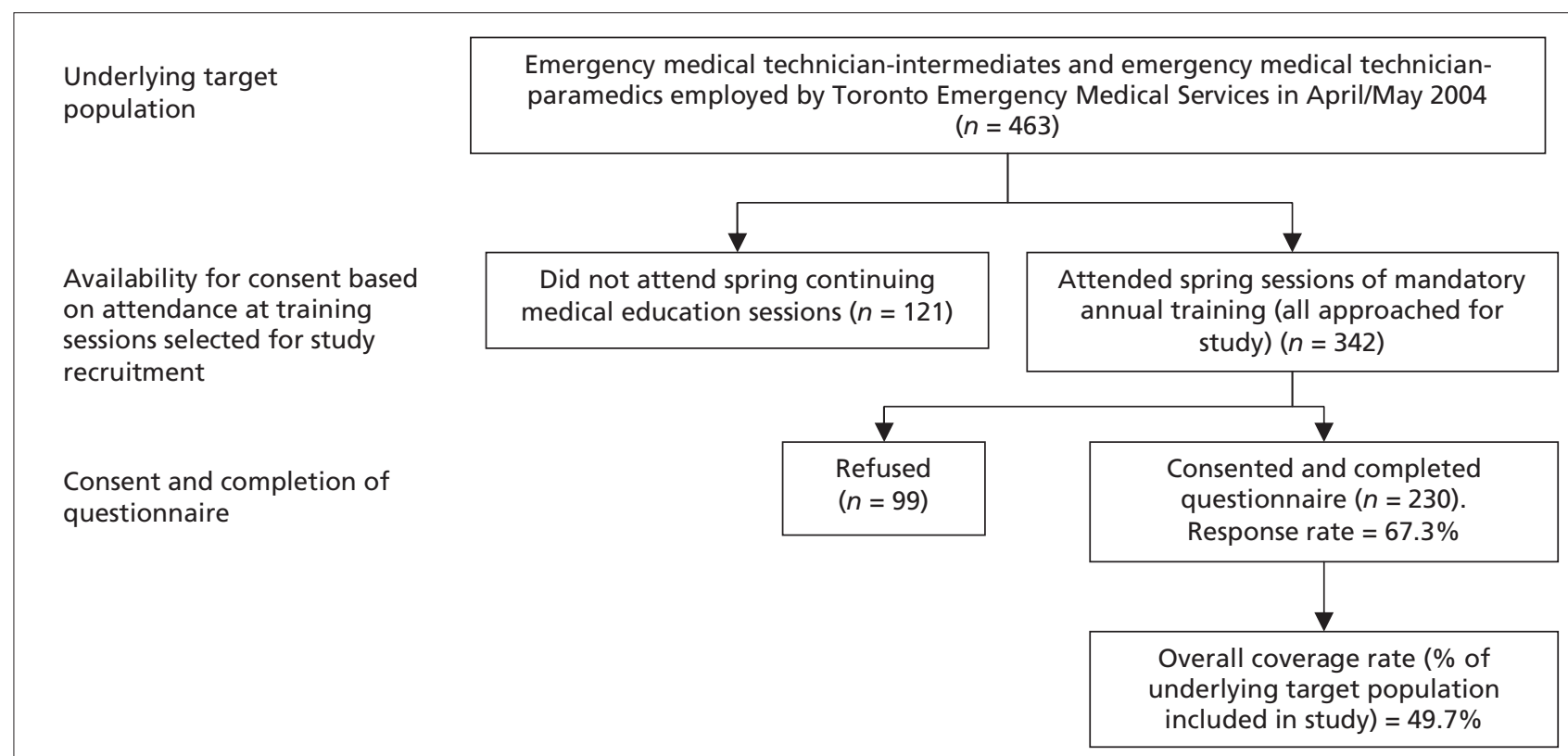

Fig. 1. Flow chart representing capture of emergency medical technicians in Toronto who responded to a communicable respiratory disease personal protective equipment survey, response and total coverage rate. 
Table 1. Characteristics of 230 respondents to a survey of Toronto emergency medical technicians on use of personal protective equipment

\begin{tabular}{|c|c|c|}
\hline \multirow{2}{*}{$\begin{array}{l}\text { Characteristic } \\
\text { Age group, yr, } n=228\end{array}$} & \multicolumn{2}{|c|}{$\begin{array}{l}\text { No. }(\%) \text { of valid } \\
\text { responses }\end{array}$} \\
\hline & & \\
\hline$\leq 29$ & 38 & $(16.7)$ \\
\hline $30-39$ & 104 & $(45.6)$ \\
\hline $40-49$ & 76 & (33.3) \\
\hline$\geq 50$ & 10 & (4.4) \\
\hline \multicolumn{3}{|l|}{ Sex $n=228$} \\
\hline Male & 177 & $(77.6)$ \\
\hline \multicolumn{3}{|l|}{ Certification level, $n=227$} \\
\hline Paramedic (v. intermediate) & 143 & $(63.0)$ \\
\hline \multicolumn{3}{|l|}{ Experience, yr, $n=225$} \\
\hline$\leq 5$ & 35 & $(15.6)$ \\
\hline $6-10$ & 51 & $(22.7)$ \\
\hline $11-15$ & 59 & $(26.2)$ \\
\hline $16-20$ & 43 & $(19.1)$ \\
\hline$>20$ & 37 & $(16.4)$ \\
\hline \multicolumn{3}{|c|}{$\begin{array}{l}\text { Worked with the Toronto service during } \\
\text { the } 2003 \text { SARS outbreak, } n=216\end{array}$} \\
\hline Yes & 202 & $(93.5)$ \\
\hline \multicolumn{3}{|c|}{ Assigned area of Toronto, $n=222$} \\
\hline Northeast & 34 & $(15.3)$ \\
\hline Northwest & 44 & $(19.8)$ \\
\hline Southeast & 76 & $(34.2)$ \\
\hline Southwest & 55 & $(24.8)$ \\
\hline$>1$ quadrant & 13 & (5.9) \\
\hline
\end{tabular}

Services, Toronto, Ont.: personal communication, 2005). Our sample is similar to the target population $(79.2 \%$ men, $56.2 \%$ paramedics). In both the sample and the population, the highest percentage of EMTs worked in the southeast (34.2\% sample, $32.1 \%$ population) and the lowest percentage worked in the northeast ( $15.3 \%$ sample, $17.7 \%$ population). In both cases, the percentages of EMTs in the northwest and southwest quadrants were $19.8 \%$ and $24.8 \%$, respectively.

Table 2 presents a summary of reports about how frequently specific items of personal protective equipment were used during the Toronto-area SARS outbreak of 2003 and a post-SARS time period immediately before the survey (2004). During the SARS outbreak, the N95-type particulate respirator mask was most often always used (91.5\%). This mask is a type of particulate-filtering disposable face-piece respirator that is certified by the National Institute for Occupational Safety and Health. The particulate filter is required to have a 95\% filter efficiency level in filtering particles with a mean diameter of greater than $0.3 \mu \mathrm{m}$. For an antimicrobial airway filter attached to the endotracheal tube, eye protection and gowns 77.6\%, 58.3\% and $41.0 \%$ of respondents, respectively, reported that they wore or used them all of the time. In contrast, the open face hood was mostly never worn (72.9\%). For other items, EMTs reported intermediate frequency use. However, post-SARS use decreased so that most of the items

Table 2. Reported frequency of use of personal protective equipment by Toronto emergency medical technicians during the SARS outbreak and subsequent routine nonoutbreak conditions

Reported frequency of use during SARS, no. (\%)

\begin{tabular}{|c|c|c|c|c|c|c|c|c|c|c|}
\hline \multirow{3}{*}{$\begin{array}{l}\text { Protective equipment } \\
\text { Eyewear, } n=211\end{array}$} & \multirow{2}{*}{\multicolumn{2}{|c|}{ Always }} & \multirow{2}{*}{\multicolumn{2}{|c|}{ Most of the time }} & \multirow{2}{*}{\multicolumn{2}{|c|}{ Sometimes }} & \multirow{2}{*}{\multicolumn{2}{|c|}{ Seldom }} & & \\
\hline & & & & & & & & & \multicolumn{2}{|c|}{ Never } \\
\hline & 123 & $(58.3)$ & 44 & (20.9) & 24 & $(11.4)$ & 6 & $(2.8)$ & 14 & $(6.6)$ \\
\hline N95, ${ }^{*} n=212$ & 194 & $(91.5)$ & 13 & $(6.1)$ & 5 & $(2.4)$ & 0 & $(0.0)$ & 0 & $(0.0)$ \\
\hline Open face hoodt $n=203$ & 16 & $(7.9)$ & 4 & (2.0) & 13 & $(6.4)$ & 22 & $(10.8)$ & 148 & (72.9) \\
\hline Face shield, $n=210$ & 75 & $(35.7)$ & 36 & $(17.1)$ & 47 & $(22.4)$ & 21 & $(10.0)$ & 31 & $(14.8)$ \\
\hline Gown, $n=210$ & 86 & $(41.0)$ & 29 & (13.8) & 28 & (13.3) & 27 & $(12.9)$ & 40 & $(19.0)$ \\
\hline Double gloves, $n=212$ & 83 & $(39.2)$ & 30 & $(14.2)$ & 39 & $(18.4)$ & 25 & $(11.8)$ & 35 & $(16.5)$ \\
\hline \multirow[t]{2}{*}{ Airway filter, $n=205$} & 159 & $(77.6)$ & 16 & $(7.8)$ & 4 & $(2.0)$ & 2 & $(1.0)$ & 24 & (11.7) \\
\hline & \multicolumn{10}{|c|}{ Reported frequency of use during routine nonoutbreak conditions } \\
\hline Eyewear, $n=228$ & 44 & (19.3) & 35 & (15.4) & 54 & $(23.7)$ & 47 & $(20.6)$ & 48 & (21.1) \\
\hline N95, $n=228$ & 48 & $(21.1)$ & 59 & $(25.9)$ & 54 & $(23.7)$ & 43 & (18.9) & 24 & (10.5) \\
\hline Face shield, $n=225$ & 15 & $(6.7)$ & 22 & (9.8) & 39 & $(17.3)$ & 69 & $(30.7)$ & 80 & (35.6) \\
\hline Gown, $n=225$ & 20 & (8.9) & 20 & (8.9) & 44 & $(19.6)$ & 62 & $(27.6)$ & 79 & (35.1) \\
\hline Double gloves, $n=225$ & 14 & $(6.2)$ & 19 & (8.4) & 41 & $(18.2)$ & 52 & $(23.1)$ & 99 & $(44.0)$ \\
\hline Airway filter, $n=221$ & 115 & $(52.0)$ & 53 & $(24.0)$ & 18 & $(8.1)$ & 7 & (3.2) & 28 & (12.7) \\
\hline
\end{tabular}

SARS $=$ severe acute respiratory syndrome.

*An N95 respirator is a type of particulate-filtering disposable facepiece respirator that is certified by the National Institute for Occupational Safety and Health. The particulate filter is required to have a $95 \%$ filter efficiency level in filtering particles with a mean diameter of $>0.3 \mu \mathrm{m}$.

tOpen face hood was not required for routine nonoutbreak conditions. 
were used with intermediate frequency (Table 2). For the face shield, gown and double gloves, the highest proportion of respondents never wore these items $(35.6 \%, 35.1 \%$ and $44.0 \%$, respectively). Of all the equipment providing personal protection, the highest reported frequency of use by respondents was the antimicrobial airway filter $(52.0 \%$ selected always).

Reasons offered for not always using a particular item of equipment are summarized in Table 3, and vary depending on the item. During the SARS outbreak, for the protective eyewear, open face hood and antimicrobial airway filter, other was the top option chosen (Table 3, 30.7\%, 54.5\% and $47.8 \%$ ). The reasons that were most frequently given for not donning these 3 items are summarized in Table 4 . Of the 103 respondents who gave other reasons for not using the open face hood, 91 indicated that availability was the reason. For the antimicrobial airway filter 12 out of 22 respondents reported unavailability. Vision problems were the most frequently reported barrier to eyewear use (14 out of 27). In the post-SARS period, the most common and consistent reason given for not donning a particular piece of personal protective equipment was that it was not perceived to be necessary (Table 3, range $27.4 \%-49.8 \%$ ). The second most common reason was that it was too rushed at the scene and there was insufficient time to don the protective gear (range 14.2\%-27.4\%). Other reasons for not donning particular personal protective equipment were more specific to each piece of equipment.

With regard to the knowledge-based testing about personal protection equipment, most respondents $(68.8 \%)$ answered 2 or 3 out of 5 questions correctly (Fig. 2). The median score was 3 out of 5 .

\section{Discussion}

Our study contributes to a very limited body of scientific literature describing infection control practices in the prehospital setting. In our representative sample of 230 providers in a major urban service, reported use of personal protection equipment was less frequent and less extensive than was required according to the standing medical directives in place at the time of the study. Actionable barriers to greater compliance with infection control procedures were identified.

During the second active outbreak of the 2003 Toronto SARS incident, the use of personal protection equipment was reported as below that required under those circumstances. This was attributed to problems with equipment availability and equipment comfort. However, since this high-profile outbreak, the use of personal protection

Table 3. Reasons chosen for not always* donning mandatory personal protective equipment by 230 Toronto emergency medical technicians during the SARS outbreak condition and subsequent routine nonoutbreak conditions

\begin{tabular}{|c|c|c|c|c|c|c|c|c|c|c|c|c|}
\hline \multirow{4}{*}{$\begin{array}{l}\text { Protective } \\
\text { equipment } \\
\text { Eyewear }\end{array}$} & \multicolumn{12}{|c|}{ Proportion of respondents, no. (\%)† } \\
\hline & \multicolumn{12}{|c|}{ SARS } \\
\hline & \multicolumn{2}{|c|}{$\begin{array}{l}\text { Too rushed at } \\
\text { scene }\end{array}$} & \multicolumn{2}{|c|}{ Not necessary } & \multicolumn{2}{|c|}{ Not required } & \multicolumn{2}{|c|}{$\begin{array}{l}\text { Impaired } \\
\text { movement }\end{array}$} & \multicolumn{2}{|c|}{ Problems with fit } & \multicolumn{2}{|c|}{ Other } \\
\hline & 18 & $(20.5)$ & 17 & $(19.3)$ & 2 & $(2.3)$ & 11 & $(12.5)$ & 17 & (19.3) & 27 & (30.7) \\
\hline N95‡ & 3 & $(16.7)$ & 4 & $(22.2)$ & 2 & $(11.1)$ & 2 & $(11.1)$ & 4 & $(22.2)$ & 3 & $(16.7)$ \\
\hline Open face hood§ & 16 & $(8.6)$ & 22 & $(11.8)$ & 14 & $(7.5)$ & 21 & $(11.2)$ & 19 & $(10.2)$ & 103 & $(55.1)$ \\
\hline Face shield & 26 & $(19.3)$ & 23 & $(17.0)$ & 6 & $(4.4)$ & 40 & $(29.6)$ & 20 & $(14.8)$ & 24 & $(17.8)$ \\
\hline Gown & 43 & (34.7) & 23 & $(18.5)$ & 14 & $(11.3)$ & 30 & $(24.2)$ & 5 & $(4.0)$ & 16 & (12.9) \\
\hline Double gloves & 34 & $(26.4)$ & 36 & $(27.9)$ & 10 & $(7.8)$ & 32 & $(24.8)$ & 9 & (7.0) & 10 & (7.8) \\
\hline \multirow[t]{2}{*}{ Airway filter } & 11 & $(23.9)$ & 10 & $(21.7)$ & 3 & $(6.5)$ & 1 & $(2.2)$ & 0 & $(0.0)$ & 22 & $(47.8)$ \\
\hline & \multicolumn{12}{|c|}{ Routine nonoutbreak } \\
\hline Eyewear & 38 & $(20.7)$ & 67 & (36.4) & 17 & $(9.2)$ & 15 & $(8.2)$ & 30 & $(16.3)$ & 37 & $(20.1)$ \\
\hline N95 & 45 & $(25.0)$ & 72 & $(40.0)$ & 31 & $(17.2)$ & 13 & $(7.2)$ & 10 & (5.6) & 15 & (8.3) \\
\hline Face shield & 34 & $(16.2)$ & 69 & (32.9) & 30 & $(14.3)$ & 43 & $(20.5)$ & 26 & $(12.4)$ & 33 & $(15.7)$ \\
\hline Gown & 53 & $(25.9)$ & 73 & (35.6) & 39 & $(19.0)$ & 44 & $(21.5)$ & 18 & (8.8) & 7 & (3.4) \\
\hline Double gloves & 30 & $(14.2)$ & 105 & $(49.8)$ & 34 & $(16.1)$ & 32 & $(15.2)$ & 17 & (8.1) & 7 & (3.3) \\
\hline Airway filter & 29 & $(27.4)$ & 29 & $(27.4)$ & 10 & $(9.4)$ & 0 & $(0.0)$ & 1 & (0.9) & 23 & $(21.7)$ \\
\hline
\end{tabular}

SARS = severe acute respiratory syndrome.

*Table includes only those respondents who did not answer "Always" to questions listed in Table 2

tIncludes number of respondents who did not answer "Always" as the reported frequency of donning equipment. These respondents were asked to select reasons for

not donning equipment and were allowed to choose more than 1 response. Therefore, the number of responses is larger than the total, which was used as the

denominator to calculate percentages. Row percentages therefore do not total $100 \%$.

¥An N95 respirator is a type of particulate-filtering disposable facepiece respirator that is certified by the National Institute for Occupational Safety and Health. The

particulate filter is required to have a $95 \%$ filter efficiency level in filtering particles with a mean diameter of $>0.3 \mu \mathrm{m}$.

$\S$ Open face hood was not required for routine nonoutbreak conditions. 
equipment during periods of nonoutbreak status have dropped off considerably to levels below that which was described in medical directives for nonoutbreak conditions.

In nonoutbreak conditions, 2 major themes emerged with respect to self-reported explanations of nonuse of personal protective equipment. One was technical difficulties with the equipment, including fit and the ease and speed of use. It appears that the "easier to use items," such as the antimicrobial airway filter, or items with a high perceived level of protection, such as an N95-type particulate respirator mask, were used with a higher frequency and consistency. This is supported by Yassi and colleagues ${ }^{11}$ from the in-hospital setting, and is intuitively understandable. EMTs reported feeling too rushed at the scene to don certain items of personal protective equipment. The support and undertaking of industrial design research will be important to create personal protective equipment that is quick, accessible and easy to deploy. Epidemiologic research may also help by identifying which items of personal protective equipment or combinations thereof are most effective in preventing the spread of disease. Health outcomes research may further define overall protocols for infection control that offer optimal prevention of disease spread, minimize the need for bulky protective equipment, and maximize compliance, without hindering patient care and the performance of necessary procedures. ${ }^{12}$

\begin{tabular}{|c|c|c|}
\hline Protective equipment & Reason given & No. \\
\hline \multirow[t]{5}{*}{ Eyewear } & Vision affected & 14 \\
\hline & Equipment unavailable & 5 \\
\hline & Forgot & 3 \\
\hline & Miscellaneous & 3 \\
\hline & Personal choice & 2 \\
\hline Total & & 27 \\
\hline \multirow[t]{6}{*}{ Open face hood } & Unavailable & 91 \\
\hline & Fit/comfort/vision & 4 \\
\hline & Felt it provides no protection & 3 \\
\hline & Forgot & 2 \\
\hline & Personal choice & 2 \\
\hline & Not part of duties & 1 \\
\hline Total & & 103 \\
\hline \multirow[t]{4}{*}{ Airway filter } & Unavailable & 12 \\
\hline & No response given & 4 \\
\hline & Partner's responsibility & 3 \\
\hline & Forgot & 3 \\
\hline Total & & 22 \\
\hline
\end{tabular}

SARS $=$ severe acute respiratory syndrome.
A second predominant reason offered for nonuse of personal protective equipment was that EMTs were not convinced of the necessity of employing all personal protective equipment despite the medical directives. They were aware that they were required to wear certain items, and they acknowledged using much of the equipment relatively consistently under high-risk circumstances. However, in their judgment, not all mandatory equipment was necessary.

This contrast between the high compliance during the SARS outbreak and lower compliance with the relevant directives during nonoutbreak deserves further attention. The "precautionary principle" approach to managing health risks has recently been described as fundamental to protecting health care workers during respiratory outbreaks. ${ }^{13}$ Where there is sufficient evidence to believe that a risk exists, action should be taken to reduce or eliminate it, even if scientific evidence is not conclusive. ${ }^{14}$ Even when there is no declared outbreak in progress, there is a risk of communicable disease spread and a hypothetical risk of the genesis of new outbreak. These risks were reflected in the "new normal" nonoutbreak directives for airway management. The importance of using personal protective equipment in nonoutbreak conditions may not have been adequately communicated to EMTs. In the event of a significant respiratory disease outbreak, there may be a delay from the time the outbreak hits the community to when it is recognized and declared an outbreak situation, since detection relies heavily on an adequate surveillance system. During that time period, the implications for noncompliance are 3-fold. First, EMTs who have not worn adequate personal protective equipment to treat patients identified as suspicious for having a respiratory illness may be quarantined after review by public health officials. During the Toronto SARS outbreak, hundreds of EMTs were quarantined, resulting in thousands of lost workdays and immeasurable impact on the system's ability to deliver

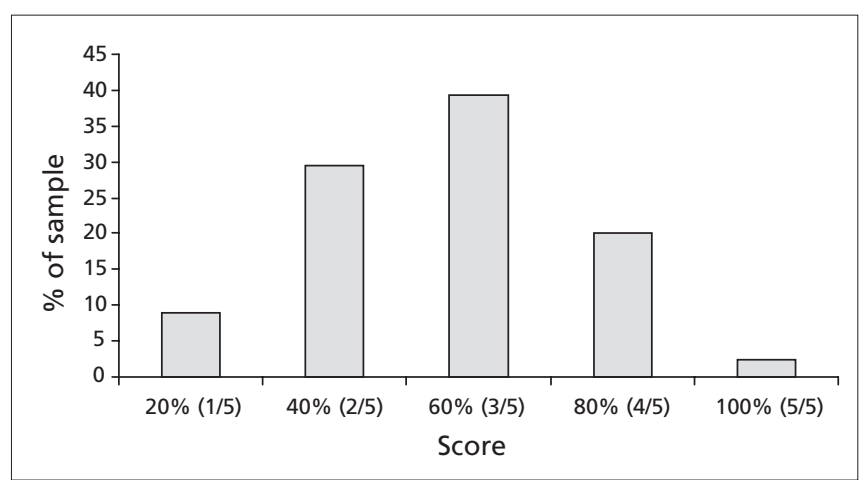

Fig. 2. Distribution of score on knowledge with regard to the 5 questions about mandatory personal protective equipment by Toronto emergency medical technicians. 
care. ${ }^{4}$ Second, the potential for spread between the community and the health care facilities is important with the EMTs who provide care in both environments, transferring patients between them. Finally, personal safety is paramount, and if a surprise outbreak occurs and EMTs are not routinely using adequate personal protective equipment, they may themselves become ill, putting their families and their coworkers at risk. In nonoutbreak conditions, additional efforts from administration may be needed to maintain risk awareness and monitor compliance.

Alternatively, by reporting nonuniversal compliance with directives, the EMTs surveyed may have been expressing their belief that the use of stringent personal protective equipment for airway management in certain patients may cause more harm than good (e.g., a trauma situation in which donning personal protective equipment may result in delays to providing lifesaving treatment or transport). Administrative directives may reflect a higher degree of risk-aversion than can practically be sustained in the field. Official directives require the lowest level of risk that is practical for reasons of public protection and concern for liability, including liability over injury to EMTs. Emergency medical technicians, on the other hand, may put greater emphasis on the care of the patient, and timely management and transport, than their own safety or hypothetical risk to the larger community. Clearly, a balance must be struck between the idea of "precautionary principle" and what is practical in the field. Dialogue will be needed to align the acceptable level of risk as perceived by management with the ability of front-line workers to provide best possible care for the patient within the constraints of working in the field while still being protected.

We have found no other studies that directly contrast outbreak conditions with nonoutbreak conditions with respect to the use of personal protective equipment for acute communicable respiratory disease outbreaks in EMTs in the prehospital setting. One study from Singapore ${ }^{15}$ documented a heightened level of compliance with protective measures by emergency services workers during the time of the SARS outbreak, but did not assess reasons for noncompliance. A small number of studies were found that examined the use of personal protective equipment for infection control in EMTs, usually for blood-borne diseases. ${ }^{16-19}$ One US study that was similar to this one found that few respondents reported consistent use of precautions for blood borne diseases. ${ }^{16}$ Other US studies of EMT knowledge and precautionary behaviour found moderate to inadequate knowledge and use of personal protective equipment to protect them from blood borne diseases. ${ }^{17-19}$ All studies pertained to nonoutbreak conditions and their findings are similar to our results. There is an enormous body of work examining the use of personal protective equipment during the SARS outbreak by hospital workers, which is reviewed indepth by Yassi and colleagues. ${ }^{11}$ Similar to the present study, technical difficulties and negative attitudes toward personal protective equipment were identified as barriers to use.

\section{Limitations}

Potential limitations of this study relate to the use of selfreports to document behaviour in the complex prehospital setting, and with the ability of respondents to recall behaviour back in time to outbreak conditions. The SARS experience was of historical significance and should be a period that is cognitively salient or easy to recall. Social desirability in responses is also a concern raised with self-reports. However, EMTs did not seem shy about admitting to noncompliance. Social desirability bias is unlikely to have led to our findings. We approached all personnel attending the mandatory training sessions during the course of the study and achieved a $67 \%$ response rate among all potential participants. Attendance in the spring training sessions (v. those offered in autumn) was completely independent of the study. There appears to be no demographic difference between attendees to the training sessions and the underlying population with respect to the very limited demographic characteristics to which we have access. We can therefore interpret our sample of 230 respondents to be a reasonable representation with respect to all members of the underlying workforce who could have participated in this study. Very few populationbased surveys have ever been conducted among prehospital personnel. Our $67 \%$ response rate from a single encounter was considerably higher than what is usually achieved in surveys of health personnel, where response rates of $30 \%$ to $40 \%$ are more common, even after repeated reminders and when using incentives for participation (Richard Myles, Manager, Computer Survey Methods. Institute for Social Research, York University, Toronto, Ont.: personal communication, 2008). ${ }^{20-21}$

\section{Conclusion}

EMT knowledge of the requirements to use personal protective equipment did not match perfectly with management directives. In addition, EMTs reported variable compliance with directives even with patients at risk, but particularly under nonoutbreak conditions. There are 
important implications of noncompliance for communicable disease control, such as putting the patients, public and providers at risk, especially during the early stage of an outbreak. Future research should focus on evaluating implementation strategies that optimize compliance with use of personal protection equipment and provide effective barriers to disease transmission.

Acknowledgment: We are grateful to emergency medical technicians at Sunnybrook Health Sciences Centre and Sunnybrook Osler Centre for Prehospital Care who contributed to survey creation and data collection, in particular Dean Popov, Tyrone Perreira, Bruce Cameron and Jamie Frank.

Competing interests: None declared.

Funding: Ms. Visentin was given financial assistance by an Ontario Graduate Scholarship and by the University of Toronto, Department of Public Health Sciences, Toronto, Ont.

\section{References}

1. Poutanen SM, Low DE, Henry B, et al. Identification of severe acute respiratory syndrome in Canada. N Engl J Med 2003;348: 1995-2001.

2. Naylor D, Basrur S, Bergeron MG, et al. Learning from SARS: renewal of public health in Canada. Ottawa (ON): Health Canada; 2003.

3. Bissell RA, Seaman KG, Bass RR, et al. Change the scope of practice of paramedics? An EMS/public health policy perspective. Prehosp Emerg Care 1999;3:140-9.

4. Verbeek PR, McClelland IW, Silverman AC, et al. Loss of paramedic availability in an urban emergency medical services system during a Severe Acute Respiratory Syndrome outbreak. Acad Emerg Med 2004;11:973-8.

5. Booth TF, Kournikakis B, Bastien N, et al. Detection of airborne severe acute respiratory syndrome (SARS) coronavirus and environmental contamination in SARS outbreak units. J Infect Dis 2005;191:1472-7.

6. Shaw K. The 2003 SARS outbreak and its impact on infection control practices. Public Health 2006;120:8-14.

7. Wallington T, Berger L, Henry B, et al. Update: Severe Acute Respiratory Syndrome - Toronto, Canada, 2003. Can Commun Dis Rep 2003;52:547-50.

8. Young J, D'Cunha C. Directives to all Ontario prehospital providers and ambulance communications services. Toronto (ON): SARS Provincial Operations Centre, Ontario Ministry of Health and Long-Term Care; 2003. Available: www.health.gov .on.ca/english/providers/program/pubhealth/sars/docs/new_normal /dir_prehospital_care.pdf (accessed 2008 Nov 28).
9. Young J, D'Cunha C. Directives to all Ontario prehospital providers and ambulance communications centres regarding management of patients with possible communicable diseases including SARS under outbreak conditions. Toronto (ON): SARS Provincial Operations Centre, Ontario Ministry of Health and Long-Term Care; 2003.Available: www.health.gov.on.ca /english/providers/program/pubhealth/sars/docs/docs2/dir_prehosp _outbreak_120703.pdf (accessed 2008 Nov 28).

10. Provincial equipment standards for Ontario ambulance services for use of Ontario land and air ambulance services. Toronto (ON): Ministry of Health and Long-Term Care; 2000.

11. Yassi A, Bryce E, Moore D, et al. Protecting the faces of health care workers: knowledge gaps and research priorities for effective protection against occupationally-acquired respiratory infectious disease. Toronto (ON): The Change Foundation; 2004.

12. Watson L, Sault W, Gwyn R, et al. Cardiopulmonary resuscitation in an out-of-hospital cardiac arrest simulation model: the "delay effect" of donning a gown. Prehosp Emerg Care 2006;10:145.

13. Campbell A. Spring of fear. Toronto (ON): SARS Commission; 2006.

14. Last JM. A dictionary of epidemiology. 4th ed. New York (NY): Oxford University Press; 2001.

15. Lateef F, Lim SH, Tan EH. New paradigm for protection: the emergency ambulance services in the time of severe acute respiratory syndrome. Prehosp Emerg Care 2004;8:304-7.

16. Smyser MS, Bryce J, Joseph JG. AIDS-related knowledge, attitudes, and precautionary behaviors among emergency medical professionals. Public Health Rep 1990;105:496-504.

17. Davidson G, Gillies P. Safe working practices and HIV infection: knowledge, attitudes, perception of risk, and policy in hospital. Qual Health Care 1993;2:21-6.

18. Gellert GA, Maxwell RM, Higgins KV, et al. AIDS and prehospital personnel: knowledge and prevention of occupational exposure. Prehospital Disaster Med 1996;11:112-6.

19. Mencl F, Birkle M, Blanda M, et al. EMT's knowledge regarding transmission of infectious disease. Prehosp Emerg Care 2000;4:57-61.

20. Salant P, Dillman DA. How to conduct your own survey. New York (NY): John Wiley \& Sons; 1994.

21. National Physician Survey Collaborative. NPS 2007 methodology and generalizability of results. Mississauga (ON): College of Family Physicians of Canada, Canadian Medical Association, Royal College of Physicians and Surgeons of Canada; 2008.

Correspondence to: Dr. Susan Bondy, Dalla Lana School of Public Health, Health Science Building, 155 College St. Toronto ON M5T 3M7; sue.bondy@utoronto.ca 


\section{Appendix 1. Paramedic Communicable Respiratory Disease Survey - April/May 2004 (Part 1 of 4) \\ Consent \\ Research Project}

The purpose of this study is to determine the preparedness of paramedics for dealing with SARS or a SARS-like respiratory illness through a written survey. Preparedness will be defined as knowledge and attitudes toward personal protective equipment (PPE). Demographic variables (for example, age, gender, years of experience not linked to personal identification) will also be collected and correlated with measures of preparedness. The data collected in this study may be used to document change over time in paramedic preparedness. The study is also serving as the research thesis for a Master's student at University of Toronto.

\section{Survey}

I agree to fill out the survey instrument, which will take approximately 10 to 20 minutes of my time. The survey will consist of a self-completed questionnaire consisting of 4 sections: behaviour, knowledge and attitudes towards PPE, and demographics.

\section{Withdrawal}

I confirm that the decision to participate in this study is entirely my own. I recognize that I may refuse to answer any question on the survey.

\section{Benefits}

I realize that there will potentially be no personal benefit to me in completing this survey. However, since this study aims to determine the level of knowledge disseminated to paramedics regarding PPE, there is also the possibility that the results of this survey will be used to better the working environment for my colleagues and myself.

\section{Confidentiality}

This study fulfills part of the requirement for a Master's thesis from the University of Toronto School of Graduate Studies. The student is supervised by a team of University of Toronto researchers from the Institute for Clinical and Evaluative Sciences and the Prehospital and Transport Medicine Research Program. All information that I give is strictly confidential. I am aware that all questionnaires for this study will only be handled by members of the research team, and will not be used for any operational or other purposes apart from those described herein. Surveys will be stored in locked cabinets at the study office. Consent forms will be stored separately from the data. Data collection forms and consent forms will be kept for the required time and then destroyed. Data released to the public, to the Ministry of Health and/or shared with other members of the prehospital medicine community will be released only in aggregated form such that I cannot be identified. My name will not appear in any of the reported results and open-ended questions and comments will be separated from other individual-level data and otherwise presented only in a manner which protects my identity.

\section{By completing this questionnaire, I give my consent to participate in this study.}

Section A: These questions will require you to think back to your past behaviour. Please place a check mark in the box under the heading that best describes your behaviour with respect the PPE items in the corresponding left hand column.

A.1: Routine PPE practices: Conditions in which patient is not at risk for a communicable respiratory illness (e.g. SARS, active TB, pandemic influenza), during nonoutbreak conditions.

Note - airway management includes:

1. BLS airway maneuvers described in the BLS Patient Care Standards for Airway Management

2. ALS airway maneuvers

3. Surgical airway maneuvers

4. Supported ventilation using Bag-Valve-Mask or endotracheal tube (ETT) or surgical airway

5. Administration of any inhaled, nebulized, or in-line endotracheal medications

Q 1. Part 1: In the last 10 encounters in which I either performed or assisted with airway management:

$\begin{array}{ccc}\text { Most of the } & \text { time } & \text { Sometimes }\end{array}$

I wore:

\begin{tabular}{|c|c|c|c|c|c|}
\hline a) Protective eyewear & {$[1]$} & [2] & [3] & [4] & [5] \\
\hline b) N95 or equivalent mask & [1] & [2] & [3] & [4] & [5] \\
\hline c) Face shield & [1] & {$[2]$} & [3] & [4] & [5] \\
\hline d) Gown & [1] & {$[2]$} & [3] & [4] & [5] \\
\hline e) Double gloves & {$[1]$} & [2] & [3] & [4] & [5] \\
\hline $\begin{array}{l}\text { I put in place a: } \\
\text { f) Hydrophobic submicron filter }\end{array}$ & [1] & [2] & [3] & [4] & [5] \\
\hline
\end{tabular}




\section{Appendix 1. Paramedic Communicable Respiratory Disease Survey - April/May 2004 (Part 2 of 4)}

Part 2: If you indicated anything other than "Always" for any item in the previous question, please indicate the reason(s) why you did not wear the PPE (check all that apply for each item):

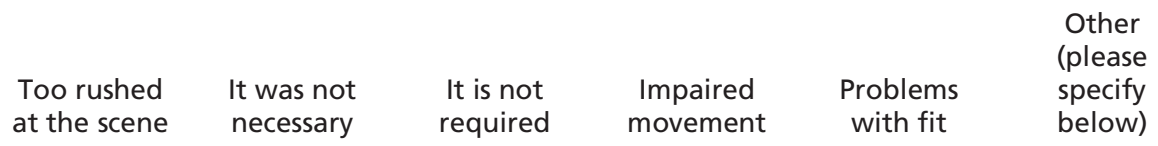

\section{I did not wear:}

a) Protective eyewear

b) N95 or equivalent mask

c) Face shield

d) Gown

e) Double gloves

I did not put in place a:

f) Hydrophobic submicron filter

$\begin{array}{ll}{[1]} & {[2]} \\ {[1]} & {[2]} \\ {[1]} & {[2]} \\ {[1]} & {[2]} \\ {[1]} & {[2]}\end{array}$

[1]
[2]

[2]

[2]

[2]

[2]

[2]
[3]

[3]

[3]

[3]

[3]
[4]

[4]

[4]

[4]

[4]

[3]

[4]
[5]

[5]

[5]

[5]

[5]
[6]

Other (specify):

Q 2. Part 1: In the last 10 encounters in which it would have been appropriate to deliver medication into an endotracheal tube (ETT), I did deliver the medication down the ETT:
Always
[1]
Most of the time
Sometimes
Seldom
Never
[3]
[4]
[5]

Part 2: If you responded to the previous question that you did deliver medication down the ETT, please indicate the reason(s) you did (check all that apply):
I felt pressure from the patch doctor
I felt pressure due to the presence of the family
I felt it was appropriate
Other (please specify below)

[1]

[2]

[3]

[4]

Other (specify):

Were you working as a Toronto Paramedic during the SARS outbreak in 2003?

[ ] Yes - proceed to section A.2 directly below.

[ ] No - proceed to section B.

A.2: Enhanced PPE practices: We ask you to think back to the second SARS outbreak of June 2003. Try to remember what you did at that point in time, when you were working on a patient who required assessment and transport and who was at risk of having SARS.

Q 3. Part 1: During the SARS outbreak, and for encounters in which I either performed or assisted with airway management:

$\begin{array}{ccc}\text { Most of the } & & \\ \text { Always } & \text { time } & \text { Sometimes }\end{array}$

\section{I wore:}

\begin{tabular}{|c|c|c|c|c|c|}
\hline a) Protective eyewear & [1] & [2] & [3] & [4] & [5] \\
\hline b) N95 or equivalent mask & {$[1]$} & [2] & [3] & [4] & [5] \\
\hline c) Open face hood & {$[1]$} & [2] & [3] & [4] & [5] \\
\hline d) Face shield & {$[1]$} & [2] & [3] & [4] & [5] \\
\hline e) Double gown & {$[1]$} & [2] & [3] & [4] & [5] \\
\hline f) Double gloves & {$[1]$} & {$[2]$} & {$[3]$} & {$[4]$} & [5] \\
\hline $\begin{array}{l}\text { I put in place a: } \\
\text { g) Hydrophobic submicron filter }\end{array}$ & [1] & [2] & [3] & [4] & [5] \\
\hline
\end{tabular}




\section{Appendix 1. Paramedic Communicable Respiratory Disease Survey - April/May 2004 (Part 3 of 4)}

Part 2: If you indicated anything other than "Always" for any item in the previous question, please indicate the reason(s) why you did not wear the PPE (check all that apply for each item):

\begin{tabular}{|c|c|c|c|c|}
\hline $\begin{array}{l}\text { Too rushed } \\
\text { at the scene }\end{array}$ & $\begin{array}{l}\text { It was not } \\
\text { necessary }\end{array}$ & $\begin{array}{l}\text { It is not } \\
\text { required }\end{array}$ & $\begin{array}{l}\text { Impairs } \\
\text { movement }\end{array}$ & $\begin{array}{l}\text { Problems } \\
\text { with fit }\end{array}$ \\
\hline
\end{tabular}

\section{I did not wear:}

\begin{tabular}{|c|c|c|c|c|c|c|}
\hline a) Protective eyewear & {$[1]$} & {$[2]$} & [3] & [4] & [5] & [6] \\
\hline b) N95 or equivalent mask & {$[1]$} & [2] & [3] & [4] & [5] & [6] \\
\hline c) Open face hood & {$[1]$} & {$[2]$} & [3] & [4] & [5] & [6] \\
\hline d) Face shield & {$[1]$} & [2] & [3] & [4] & {$[5]$} & [6] \\
\hline e) Double gown & {$[1]$} & [2] & [3] & [4] & [5] & [6] \\
\hline f) Double gloves & {$[1]$} & [2] & [3] & [4] & [5] & [6] \\
\hline $\begin{array}{l}\text { I did not put in place a: } \\
\text { g) Hydrophobic submicron filter }\end{array}$ & [1] & [2] & [3] & [4] & [5] & [6] \\
\hline
\end{tabular}

Section B: Please place a check mark in the box next to the correct answer.

Q 4. When treating a patient with nebulized medications in nonoutbreak conditions, a paramedic must wear the following PPE:

[1] N95 or equivalent respirator and gloves

[2] N95 or equivalent respirator, gloves, face shield and gown

[3] N95 or equivalent respirator, gloves and protective eyewear

[4] N95 or equivalent respirator, gloves and protective eyewear, gown

Q 5. What PPE must be worn if the patient is a splash/spray risk, patient who is considered to be at risk of having a communicable respiratory illness?

[1] N95 or equivalent respirator and gloves

[2] N95 or equivalent respirator, gloves, face shield and gown

[3] N95 or equivalent respirator, gloves and protective eyewear

[4] N95 or equivalent respirator, double gloves, protective eyewear, head cover, gown and face shield

Q 6. N95 or equivalent respirators must be fit tested to ensure proper protection.

[1] True

[2] False

Q 7. You are treating patient who is considered to be at risk of having a communicable respiratory illness and they are in mild distress with a $\mathrm{SpO}_{2}=95 \%$ on room air.

When there is a risk of being exposed to respiratory secretions the patient should be given:

[1] A N95 or equivalent respirator

[2] A surgical mask with or without nasal cannula oxygen

[3] A low flow high oxygen concentration mask with hydrophobic submicron filter

[4] A nonrebreather mask

Q 8. The paramedic driving the ambulance should wear all protective gear enroute to hospital when transporting a patient considered to be at risk of having a communicable respiratory illness.

[1] True

[2] False

Continued on next page 


\section{Appendix 1. Paramedic Communicable Respiratory Disease Survey - April/May 2004 (Part 4 of 4) \\ Section C: These questions require you to place a check mark in the box that corresponds to your personal beliefs regarding the PPE indicated in the left hand column}

Q 9. Part 1: I believe the listed PPE should be required under the following circumstances:

\begin{tabular}{|c|c|c|c|c|c|c|c|c|}
\hline & \multicolumn{5}{|c|}{$\begin{array}{l}\text { Only during } \\
\text { outbreak } \\
\text { situations, and } \\
\text { only for patients } \\
\text { who are at risk }\end{array}$} & \multicolumn{2}{|c|}{$\begin{array}{l}\text { During outbreak } \\
\text { situations, for all } \\
\text { calls }\end{array}$} & \multirow{2}{*}{$\begin{array}{c}\text { Always, under all } \\
\text { circumstances } \\
{[5]}\end{array}$} \\
\hline a) Gowns & [1] & \multicolumn{4}{|c|}{ [3] } & \multicolumn{2}{|r|}{ [4] } & \\
\hline b) Coveralls & [1] & \multicolumn{4}{|c|}{ [3] } & \multicolumn{2}{|r|}{ [4] } & [5] \\
\hline c) Full mask respirator & [1] & \multicolumn{4}{|c|}{ [3] } & \multicolumn{2}{|r|}{ [4] } & {$[5]$} \\
\hline $\begin{array}{l}\text { d) Personal protective } \\
\text { systems (i.e., Stryker } \\
\text { suit) }\end{array}$ & [1] & \multicolumn{4}{|c|}{ [3] } & \multicolumn{2}{|r|}{ [4] } & [5] \\
\hline \multicolumn{9}{|c|}{$\begin{array}{l}\text { Part 2: If indicated anything other than required "Always, under all circumstances," what are your reasons why? } \\
\text { (Please check all that apply) }\end{array}$} \\
\hline & $\begin{array}{l}\text { Impedes my } \\
\text { ability to } \\
\text { physically do } \\
\text { my duties }\end{array}$ & $\begin{array}{l}\text { Too costly to } \\
\text { implement in } \\
\text { all } \\
\text { ambulances }\end{array}$ & $\begin{array}{l}\text { Take } \\
\text { to pi } \\
\text { up } \\
\text { s }\end{array}$ & $\begin{array}{l}\text { to long } \\
\text { it on/set } \\
\text { at the } \\
\text { cene }\end{array}$ & \multicolumn{2}{|c|}{$\begin{array}{l}\text { Too difficult } \\
\text { to use } \\
\text { properly }\end{array}$} & $\begin{array}{l}\text { It is } \\
\text { ineffective }\end{array}$ & $\begin{array}{l}\text { Other (please } \\
\text { specify } \\
\text { below) }\end{array}$ \\
\hline a) Gowns & [1] & [2] & & [3] & \multicolumn{2}{|c|}{ [4] } & [5] & {$[6]$} \\
\hline b) Coveralls & [1] & [2] & & [3] & \multicolumn{2}{|c|}{ [4] } & [5] & [6] \\
\hline c) Full mask respirator & [1] & [2] & & [3] & \multicolumn{2}{|c|}{ [4] } & [5] & [6] \\
\hline $\begin{array}{l}\text { d) Personal protective } \\
\text { systems (i.e., Stryker } \\
\text { suit) } \\
\text { Other (specify): }\end{array}$ & [1] & [2] & & [3] & [4] & & {$[5]$} & {$[6]$} \\
\hline
\end{tabular}

Section D: Demographics

You are nearly done! Thank you in advance for completing this survey.

Q 10. What is your age?
[1] Under 24
[2] 25-29
[3] 30-39
[4] 40-49
[5] 50-59
$[6] 60+$

Q 11. What is your sex

[1] Male

[2] Female

Q 12. What is the highest level of education completed, not including paramedic training?
[1] High school
[3] University - Undergraduate level
[2] College
[4] University - Graduate level

[5] Other (specify):

Q 13. What is your paramedic level?
[1] PCP
[2] Level 2
[3] ACP
[4] CCP

Q 14. In what quadrant do you work routinely?
[1] Northeast
[2] Northwest
[3] Southeast
[4] Southwest
[5] $>1$ quadrant

Q 15. How many years have you been working as a paramedic? (including all levels and systems you have worked in)
[1] 0 to 5
[2] 6 to 10
[3] 11 to 15
[4] 16 to 20
[5] 21 to 25
[6] 26 to 30
[7] 30 years +

Q 16. Do you live with your spouse/partner?

[1] Yes

[2] No

Q 17. Do you have children under 18 ?

[1] Yes

[2] No

Please write your comments here:

Thank you very much for taking the time to complete this survey! 